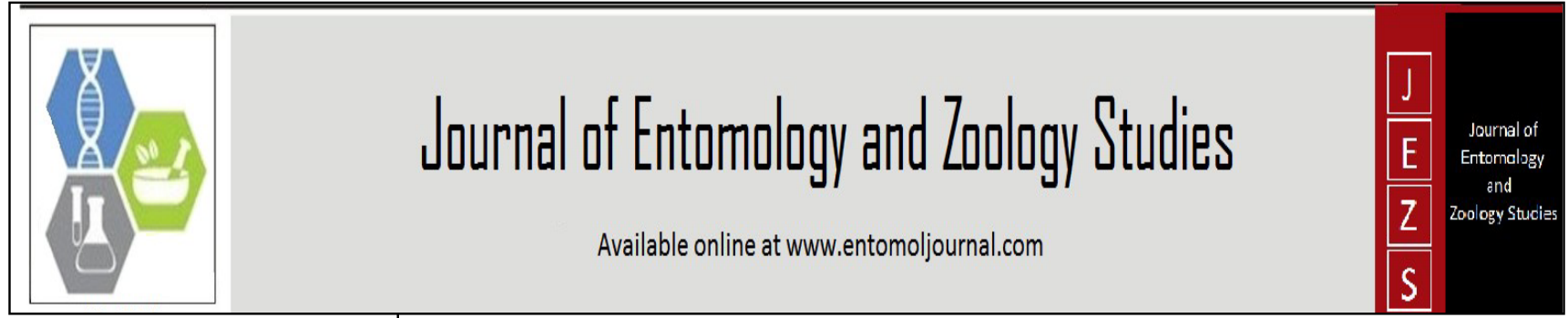

E-ISSN: 2320-7078 P-ISSN: 2349-6800 JEZS 2017; 5(2): 207-208

(C) 2017 JEZS

Received: 16-01-2017 Accepted: 17-02-2017

Mark Ian Cooper

Department of Biologica Sciences, University of Cape Town, Rondebosch 7701 Republic of South Africa
Correspondence Mark Ian Cooper Department of Biological Sciences, University of Cape Town, Rondebosch 7701, Republic of South Africa

\section{Size matters in myriapod copulation}

\section{Mark Ian Cooper}

\section{Abstract}

Size correlates with mating in Centrobolus. I tested for the presence of relationships between male length and copulation duration in $C$. inscriptus by performing double mating. Males differed from females in mass, length, and dorsal tergite width. Male length was positively related to the duration of the first mating but negatively related to the duration of the second mating which related to sexual size dimorphism (SSD).

Keywords: Arthropods, size, Centrobolus, copulation, myriapod, length

\section{Introduction}

Sizes can influence the duration of copulation e. g. Drosophila melanogaster ${ }^{[1]}$. Size and morph are drivers of copulation duration ${ }^{[2]}$. These factors may be interdependent ${ }^{[3]}$. In millipedes, size and SSD are related to copulation duration ${ }^{[4-6]}$. Here the present study tested the presence of a relationship between male length and copulation duration in second matings. Four alternative hypotheses are positive and negative relationships between length and first and second copulation durations, respectively.

\section{Materials and methods}

Millipedes were collected in April 1995 from Zululand (Twin streams farm, Mtunzini). Live specimens of each sex were transported to a laboratory where conditions were kept under a constant regime of $25{ }^{\circ} \mathrm{C}$ temperature; $70 \%$ relative humidity; 12: 12 hrs light-dark cycle. Food was provided in the form of fresh vegetables ad libitum. Individuals had unknown mating histories. Unisex groups were housed in plastic containers containing moist vermiculite ( $\pm 5 \mathrm{~cm}$ deep) for 10 days before commencing the mating experiments. Three measurements were taken for individuals once copula pairs disengaged; mass (accurate to $0.01 \mathrm{~g}$ ), length $(\mathrm{mm})$, and dorsal tergite width $(\mathrm{mm})$. Animals were placed into glass mating arenas $(30 \mathrm{X} 22$ X $22 \mathrm{~mm}$ ). Individuals were marked on the posterior segments with coloured tipex fluid (perfect A16) prior to mating. This allowed data from individuals to be integrated. Double mating with females was allowed. Approximately five minutes after establishing pairs were removed from the mating arena and placed into plastic beakers (13 cm diameter). This prevented interference from other males and allowed timing of the copulation durations.

\subsection{Statistical analyses}

Statistical analyses were performed using Statgraphics (version 6.0) and Statistica. Morphometric data were tested for normality before comparing males and females using Student's t-test and Wilcoxon matched-pairs test's. Pearson's correlation coefficients were used to analyse any other relationships. Coefficients of variation (CV) were calculated by dividing the standard deviations by their means and multiplying by $100 \%$.

\section{Results}

Males differ from females in mass (student's t-test: $\mathrm{t}=9.38, d . f .=95, p<0.05)$, length $(\mathrm{t}=-2$. $19, d . f .=95, p<0.005)$, and dorsal tergite width $(\mathrm{t}=24.21, d . f .=95, p<0.005)$ (Fig. 1$)$. Independent samples showed males and females differed in mass $(\mathrm{T}=554, \mathrm{n}=88, \mathrm{P}=0)$, length $(\mathrm{T}=485, \mathrm{n}=88, \mathrm{P}=0.0)$, and width $(\mathrm{T}=2.5, \mathrm{n}=88, \mathrm{P}=0)$. In double mating, male length related to the duration of the first mating $\left(\mathrm{r}_{\mathrm{s}}=0.30 \mathrm{n}=46, \mathrm{P}=0.04\right)$ but negatively related to duration of the second mating $\left(\mathrm{r}_{\mathrm{s}}=-0.35, \mathrm{n}=46, \mathrm{P}=0.02\right) .1^{\text {st }}$ copulation duration was not dependent on SSD within copulating pairs $(\mathrm{r}=0.2, \mathrm{n}=46, P>0.05)$, and 2nd copulation durations depended on SSD $(\mathrm{r}=0.41, \mathrm{n}=46, \mathrm{P}=0.004)$. Marginally lower variance of male length $(\mathrm{CV}=3.4-4.7 \%) c$. $f$. female length $(\mathrm{CV}=4.5-6.0 \%)$. Length/width were unrelated $(\mathrm{r}=0.13, \mathrm{n}=46 \mathrm{P}=0.39)$.

$$
\text { } 207 \text { }
$$




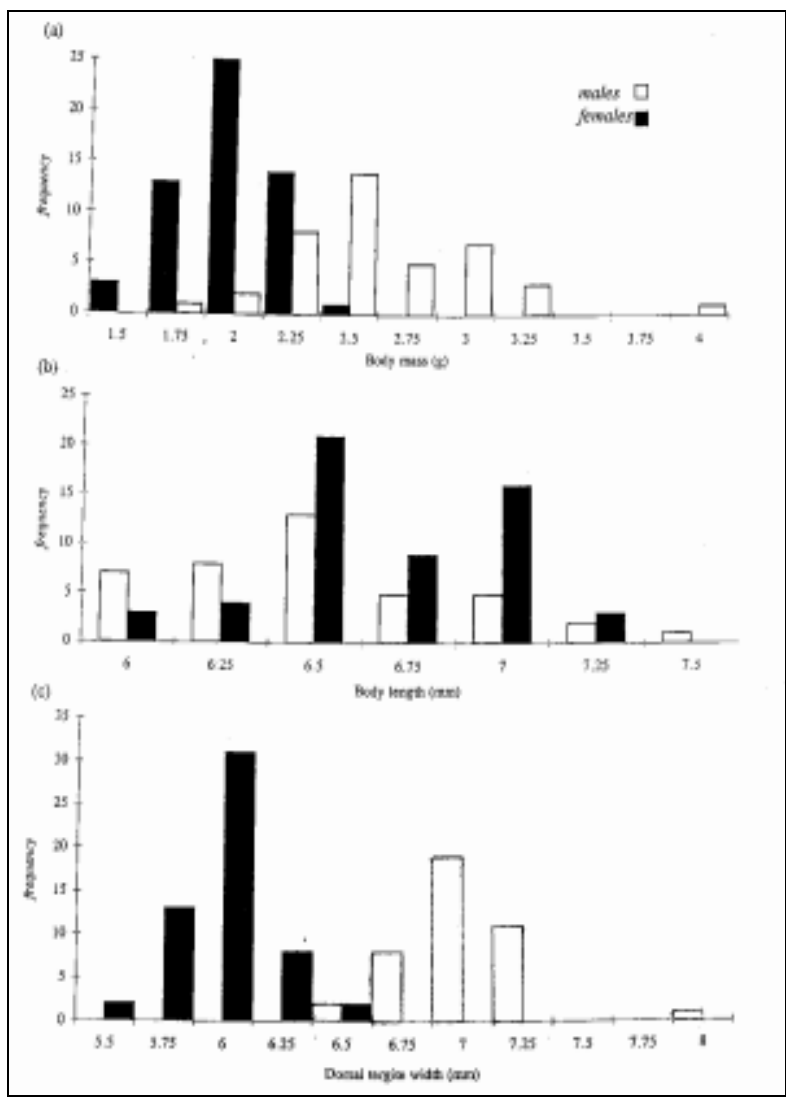

Fig 1: Bar graph showing the three sexually dimorphic parameters in Centrobolus inscriptus: (a) mass, (b) length, (c) width.

Table 2: Two independent morphometric measurements of length for Centrobolus inscriptus.

\begin{tabular}{|c|c|c|c|c|}
\hline Parameter & \multicolumn{2}{|c|}{ Male length (mm) } & \multicolumn{2}{c|}{ Female length (mm) } \\
\hline $\mathrm{n}$ & 56 & 88 & 41 & 88 \\
\hline Mean (SD) & $67(3.15)$ & $59(2)$ & $65(3.93)$ & $67(3)$ \\
\hline $\mathrm{CV}$ & 4.7 & 3.4 & 6.0 & 4.5 \\
\hline
\end{tabular}

\section{Discussion}

Hypotheses were tested and two relationships between male length and copulation duration found. Copulations of first males positively related to male length. Absence of a relationship between male length and width shows no autocorrelation and length as causal in maximizing cylindrical millipede's volume. Lower variance of male lengths relative to female lengths is probably due to reversed SSD. Variance may be caused by female stadia ${ }^{[7]}$. C. inscriptus ratio of length: width is beyond 7-9.5 range for Centrobolus $\left.{ }^{[5,} 8\right]$. Morphometric trends suggest males adapt for increased mobility and control copulation based on length. Males appear to control copulation with length to assure paternity ${ }^{[9]}$. The negative relationship between copulation durations of second males - and size occurs in mammals ${ }^{[10]}$. Length affects mate-choice in fish ${ }^{[11]}$. Length variance was addressed ${ }^{[12]}$.

\section{Conclusion}

Copulation duration related to male length in double mating C. inscriptus. Second mating intra-pair SSD is under female control and affects ejaculate precedence.

\section{Acknowledgements}

Mike Picker commented on the manuscript.

\section{References}

1. Lefranc A, Bungaard J. The influence of male and female body size on copulation duration and fecundity in Drosophila melanogaster. Hereditas. 2000; 132:243-247.

2. Wong-Muñoz J, Anderson $\mathrm{CN}$, Munguía-Steyer R, Córdoba-Aguilar A. Body Size and Morph as Drivers of Copulation Duration in a Male Dimorphic Damselfly. Ethology. 2013; 119(5):407-416.

3. Walzer A, Schausberger P. Interdependent effects of male and female body size plasticity on mating behaviour of predatory mites. Animal Behaviour. 2015; 100:96-105.

4. Cooper MI. Sexual conflicts over duration of copulation in Centrobolus inscriptus (Attems). Journal of Entomology and Zoology Studies. 2016; 4(6): 852-854.

5. Cooper MI. The relative sexual size dimorphism of Centrobolus inscriptus (Attems) compared to 18 congenerics. Journal of Entomology and Zoology Studies 2016; 4(6):504-505.

6. Cooper MI. The influence of male body mass on copulation duration in Centrobolus inscriptus (Attems). Journal of Entomology and Zoology Studies 2016; 4(6):804-805.

7. Cooper MI. Sexual bimaturism in the millipede Centrobolus inscriptus Attems (Spirobolida: Trigoniulidae). Journal of Entomology and Zoology Studies. 2016; 4(3):86-87.

8. Lawrence RF. The centipedes and millipedes of southern Africa: A guide. Cape Town \& Rotterdam: A.A. Balkema, 1983, XII + 148.

9. Cooper MI Competition affected by re-mating interval in a myriapod. Journal of Entomology and Zoology Studies. 2015; 3(4):77-78.

10. Stallmann RR, Harcourt AH. Size matters: the allometry of copulatory duration in mammals. Biological Journal of the Linnean Society 2006; 87(2):185-193.

11. Witte K, Ryan MJ. Male body length influences matechoice copying in the sailfin molly Poecilia latipinna. Behavioral Ecology. 1998; 9(5):534-539.

12. Plavcan JM. Body Size, Size Variation, and Sexual Size Dimorphism in Early Homo. Current Anthropology. 2012; 53 (S6):S409-S423. 